\title{
Genetic and epigenetic alterations in the GNAS locus and clinical consequences in Pseudohypoparathyroidism: Italian common healthcare pathways adoption
}

L. de Sanctis ${ }^{1 *}$, F. Giachero ${ }^{2}$, G. Mantovani ${ }^{3}$, G. Weber ${ }^{4}$, M. Salerno ${ }^{5}$, G. I. Baroncelli' ${ }^{6}$, F. M. Elli ${ }^{3}$, P. Matarazzo ${ }^{7}$, M. Wasniewska ${ }^{8}$, L. Mazzanti ${ }^{9}$, G. Scirè ${ }^{10}$, D. Tessaris ${ }^{1}$ and On behalf of the Study Group Endocrine diseases due to altered function of Gsa protein of the Italian Society of Pediatric Endocrinology and Diabetology (ISPED)

\begin{abstract}
Background: Genetic and epigenetic alterations in the GNAS locus are responsible for the Gsa protein dysfunctions causing Pseudohypoparathyroidism (PHP) type $\mathrm{la} / \mathrm{c}$ and $\mathrm{lb}$, respectively. For these heterogeneous diseases characterized by multiple hormone resistances and Albright's Hereditary Osteodystrophy (AHO) the current classification results inadequate because of the clinical overlap between molecular subtypes and a standard clinical approach is still missing.

In the present paper several members of the Study Group Endocrine diseases due to altered function of Gsa protein of the Italian Society of Pediatric Endocrinology and Diabetology (ISPED) have reviewed and updated the clinical-molecular data of the largest case series of (epi)/genetically characterized AHO/PHP patients; they then produced a common healthcare pathway for patients with these disorders.

Methods: The molecular analysis of the GNAS gene and locus identified the causal alteration in 74 subjects (46 genetic and 28 epigenetic mutations). The clinical data at the diagnosis and their evolution during up to 15 years follow-up were collected using two different cards.

Results: In patients with genetic mutations the growth impairment worsen during the time, while obesity prevalence decreases; subcutaneous ossifications seem specific for this group. Brachydactyly has been detected in half of the subjects with epigenetic alterations, in which the disease overts later in life, often with symptomatic hypocalcaemia, and also early TSH and GHRH resistances have been recorded.
\end{abstract}

Conclusions: A dedicated healthcare pathway addressing all these aspects in a systematic way would improve the clinical management, allowing an earlier recognition of some PHP features, the optimization of their medical treatment and a better clinical-oriented molecular analysis. Furthermore, standardized follow-up data would provide new insight into less known aspects.

Keywords: GNAS gene, GNAS locus, Pseudohypoparathyroidism, Albright Hereditary Osteodystrophy, PTH resistance

\footnotetext{
* Correspondence: luisa.desanctis@unito.it

${ }^{1}$ Department of Public Health and Pediatric Sciences, University of Turin -

Regina Margherita Children's Hospital - Health and Science City,

Subintensiva Allargata Prima Infanzia, Piazza Polonia 94, 10126 Torino, Italy

Full list of author information is available at the end of the article
} 


\section{Background}

Pseudohypoparathyroidism (PHP) defines a group of rare heterogeneous metabolic disorders, characterized by resistance to the peripheral action of $\mathrm{PTH}$, the most important hormone regulating the calcium and phosphorus homeostasis [1, 2]. Several mutations of the GNAS gene (20q13.32) and epigenetic alterations within its locus have been described as causes of the different forms of PHP type I (i.e. PHP-Ia, PHP-Ib, PHP-Ic). They all induce an impaired function of the Gs $\alpha$ protein (the $\alpha$-subunit of the heterotrimeric stimulatory $G$ protein), which regulates the adenylate cyclase activity in the signaling pathway of various peptide hormones binding the G-protein-coupled receptors (GPCR): PTH, TSH, GHRH, gonadotropins, $\mathrm{ACTH}$, and calcitonin among others $[1,3]$.

Inactivating mutations in exons $1-13$ of the maternal copy of the GNAS gene lead to PHP-Ia, whose phenotype encompasses the Albright Hereditary Osteodystrophy (AHO) signs including short stature (SS), brachydactyly $(\mathrm{BR})$, obesity $(\mathrm{OB})$, round face $(\mathrm{RF})$, subcutaneous ossifications (SO) and mental retardation (MR) together with multiple resistances to PTH (rPTH), TSH (rTSH) and to other aforementioned GPCR-binding hormones. Altered response to other hormones (i.e. insulin) were recently debated as part of the phenotype $[4,5]$. In several subjects with the same clinical features but normal Gs $\alpha$ protein in vitro activity (i.e. PHP-Ic patients) mutations affecting the C-term region of the GNAS gene and its binding site to the GPCRs were described [6, 7]. A different form of the disease, named Pseudopseudohypoparathyroidism (PPHP) and characterized by isolated AHO features without hormone resistances, occurs if germline mutations involve the paternal copy of the gene [8]. PHP-Ia and PPHP may affect members of the same family and such different clinical presentation have been explained by tissue-specific differential methylation patterns [9].

The PHP-Ib subgroup is classically defined by $\mathrm{rPTH}$, without $\mathrm{AHO}$ signs nor other hormone disruptions, except at times rTSH [1]; and it is caused by epigenetic alterations at the GNAS locus, that is one of the most complex ones in the human genome. In addition to $\mathrm{Gs} \alpha$, it gives rise to four other transcripts (XL $\alpha$ s, A/B, NESP55 and AS) [10] whose expression is regulated by an imprinting mechanism [11]. The loss of methylation on maternal exon $A / B$ is the most common alteration: in the familial autosomal dominant form of the disease (i.e. AD-PHP-Ib) this involves deletions in the STX16 gene, although in some families it was also related to NESP55 and NESP-AS alterations [12, 13]. Conversely, the sporadic form of PHP-Ib shows multiple alterations of the imprinting pattern (loss of methylation at NESP-AS, XL $\alpha$ s, A/B and gain of methylation at NESP55); paternal isodisomy of chromosome $20 \mathrm{q}$ involving the GNAS locus has also been described in some patients with large imprinting disruptions $[14,15]$.
In the last years several independent studies have reported complex clinical phenotype encompassing AHO features and multiple hormone resistances in patients with molecular diagnosis of PHP-Ib, suggesting that altered methylation may play a similar role to structural mutations in the pathogenesis of the disease [16-19]. Conversely, in subjects with $\mathrm{AHO}$ and multihormone resistances, with normal Gs $\alpha$ protein in vitro activity, clinically indicated as having the PHP-Ic subtype, the same alterations found in the GNAS locus have recently been described [19]. Furthermore, GNAS gene mutations were described also in patients with Progressive Osseous Heteroplasia $(\mathrm{POH})$ and primary Osteoma Cutis (OC) broadening the spectrum of Gs $\alpha$-related disorders and representing two important differential diagnosis [20, 21]. Thus the clinical overlap between different genotypes made the current classification inadequate pointing out the need of an update.

On the other hand current literature data show a lack of knowledge about some clinical features [22]: prevalence of several clinical signs are often debated, and to date only few studies have considered the evolution of the disease over the time. Likewise, due to the rareness of the disease, a common clinical approach is still missing and no standards or recommendations are available for the clinical routine.

In the largest series of PHP patients with a confirmed molecular diagnosis this work attempts to describe the genotype-phenotype correlation and to give a first insight into the evolution of the disease in a mainly pediatric population. To improve the standardization of the clinical management and further data collection of PHP patients we also introduce a possible flowchart for a common healthcare pathway.

\section{Methods \\ Patients}

Since 1999, patients with clinical diagnosis of PHP, defined as rPTH (i.e. raised serum PTH levels, in presence of hyperphosphatemia and normo- or hypocalcaemia, despite normal renal function [16]) isolated or associated to rTSH or AHO signs, were collected countrywide by the main Italian referee Centers for Pediatric Endocrinology within the research project Molecular analysis of the GNAS gene in subjects with suspected PHP of the Study Group Endocrine diseases due to altered function of Gs $\alpha$ protein of the Italian Society of Pediatric Endocrinology and Diabetology (ISPED). DNA samples and clinical data were sent to the Department of Public Health and Pediatrics of the University of Turin, where the molecular analyses were performed by searching for mutations within the coding region and intron-exon boundaries of the GNAS gene. 
In patients with wild-type GNAS sequence, the cooperation of the Endocrinology Unit at Fondazione IRCCS Ca' Granda Policlinico - University of Milan allowed to expand the molecular diagnosis by further methylation analysis on the GNAS locus.

The causal alteration was detected in a total of 74 subjects, from 69 unrelated families. The principal clinical features and the molecular characterization of the case series are presented in Tables 1, 2 and 3.

Structural mutations in exons 1-13 were detected in 42 subjects (4 couples of siblings), thus diagnosed as PHP-Ia; in 4 patients (A17, A18, A45 and A46) the phenotype was characterized by early and widespread subcutaneous ossifications, raising a differential diagnosis with $\mathrm{POH}$. Four other patients (A7, A12, A13 and A40). 2 of them siblings, harbored the mutation affecting the C-terminal region of the Gs $\alpha$ protein (exon 13), associated to normal in vitro Gsa activity [6], allowing the definition of the more rarely described PHP-Ic. The pathogenicity of each variant was checked within the 1000 genomes database (www.internationalgenome.org) and the mutation nomenclature within the Leiden Open Variation Database (www.lovd.nl/3.0).

All 28 patients with epigenetic alterations in the GNAS locus came from unrelated families. Altered methylation patterns in multiple DMRs were detected in most of them $(n=25, \mathrm{~B} 1-25)$, allowing the diagnosis of sporadic PHP-Ib. In the 3 remaining patients (B26-28) a deletion on the STX16 gene responsible for the familial form of the disease (AD-PHP-Ib) has been identified.

Clinical data at the time of the enrollment and during the follow-up period were collected through 2 different recording cards. The first one has been conceived to assess the typical PHP signs, leading to the clinical suspicion of the disease, i.e. the presence/absence of the AHO signs and of PTH and TSH resistances; subsequently, through a new research project, named Clinical Update about patients with $P H P / A H O$ a new follow-up card has been drawn to collect further clinical details about patients with a confirmed molecular diagnosis. In particular it has been focused on the evolution of auxological parameters, on the possible late onset of some AHO signs and other hormone resistances, overall the less known ones. This second part of the study is still going on in a clinical network with the aim of taking care of the patients during the whole pediatric age, and when possible also later in life (through cooperation with adult age endocrinologists).
Informed consent was obtained for all patients involved in the study from either parents (or legal guardian), or from the patients themselves in case of adults.

In the 2 cards, in addition to rPTH and the onset age, rTSH was considered in presence of clinical or subclinical hypothyroidism (i.e. high serum TSH, with or without low serum level of free Thyroxine); other hormone defects (resistances to GHRH (rGHRH), FSH/LH (rGn) and reduced insulin sensitivity) were identified by hormone increased basal levels or altered response to the specific stimulation tests.

SS was diagnosed as height below the 3rd percentile for chronological age, while $\mathrm{OB}$ was defined as Body Mass Index (BMI) above the 97th percentile in children (SDS $\geq 1.88$ ) and above $30 \mathrm{~kg} / \mathrm{m}^{2}$ in adults; overweight (BMI $\geq 85$ th percentile or $\mathrm{SDS} \geq 1.036$ in children and BMI $\geq 25 \mathrm{~kg} / \mathrm{m} 2$ in adults) was also marked but not considered for clinical diagnosis of PHP. The aforementioned auxological parameters have been evaluated through the software Growth Calculator 3.0 (available on the ISPED's web site http://www.siedp.it/pagina/ $151 /$ growth+calculator +3 ) that gives access to several growthcharts designed on different populations. Since our patients had Italian origin, we employed the Italian charts (INeS' Charts and Cacciari's Charts [23]) in order to obtain uniformity.

BR was recorded if clinically present with positive Archibald's sign (in case of shortening of IV-V metacarpals) and/or shown by the Metacarpophalangeal profile (MPP, indicating at least one metacarpal bone or distal phalanx shorter than 2 SD score - SDS) [16]. SO were reported if clinically evident or confirmed by X-rays; in few patients bioptic analysis has been performed before surgical removal.

RF was reported as clinical feature, while MR was marked in case of psychomotor retardation or delayed speech or need of assistant teacher and extra school help.

\section{Molecular analysis \\ GNAS gene analysis}

Genomic DNA was extracted from peripheral blood leukocytes using the commercial kit PUREGENE ${ }^{\oplus}$ DNA Purification Kit, Gentra. The 13 coding exons of the GNAS gene, together with the exon-intron boundaries regions were amplified by PCR using the ABI PRISM ${ }^{\circ}$ BigDye Terminator Cycle Sequencing Kit and then

Table 1 Principal features at diagnosis in the 2 groups of patients with GNAS gene mutations and GNAS locus altered methylation

\begin{tabular}{llllllll}
\hline & $N^{\circ}$ Subjects & Sex: F/M & Age & Ca $(\mathrm{mEq} / \mathrm{l})$ & $\mathrm{P}(\mathrm{mg} / \mathrm{dl})$ & $\mathrm{PTH}(\mathrm{pg} / \mathrm{ml})$ & $\mathrm{TSH}(\mu \mathrm{U} / \mathrm{ml})$ \\
\hline Gene mutation & 46 & $29 / 17$ & $4.8(0.1-23.4)$ & $4.3(2.25-6.7)$ & $6.8(4-12.2)$ & $308(15.6-1200)$ & $7.8(1.6-22.1)$ \\
Locus altered methylation & 28 & $16 / 12$ & $10.5(0.5-65)$ & $3.6(1.9-9.2)$ & $6.9(3.6-10.5)$ & $358(128-1532)$ & $5(3.36-8.95)$
\end{tabular}

Legend. Sex: Females/Males; Age: median age in years (range); Ca: median total serum Calcium levels (range); P: median serum Phosphate level (range); PTH: median serum PTH (range); TSH: median serum TSH level (range) 
Table 2 Clinical features and molecular characterization of patients with GNAS gene mutations

\begin{tabular}{|c|c|c|c|c|c|}
\hline $\mathrm{Pt}$ & Sex & Age & AHO signs & Hormone resistances & GNAS gene mutation \\
\hline $\mathrm{A} 1$ & $\mathrm{~F}$ & 0.25 & $\mathrm{OB}$ & rPTH, rTSH & $c .240+1 G>T$ \\
\hline $\mathrm{A} 2$ & $\mathrm{~F}$ & 2 & $\mathrm{BR}, \mathrm{SO}, \mathrm{MR},(\mathrm{OB}), \mathrm{RF}$ & rPTH, rTSH (12) & c.347_348insC \\
\hline A3 & M & 3.68 & $\mathrm{BR}, \mathrm{MR}, \mathrm{OB}, \mathrm{RF}$ & rPTH, rTSH & c.347_348insT \\
\hline A4 & $\mathrm{F}$ & 1.53 & $\mathrm{BR}, \mathrm{SS},(\mathrm{OB}), \mathrm{RF}$ & rPTH, rTSH & c. $1009 C>T$ \\
\hline A5 & $\mathrm{F}$ & 3.31 & $\mathrm{BR}^{*}, \mathrm{MR}, \mathrm{OB}, \mathrm{RF}$ & rPTH, rTSH & c.421_422del \\
\hline A6 & M & 4.72 & $\mathrm{BR}, \mathrm{SO}, \mathrm{MR},(\mathrm{OB} / \mathrm{OW}), \mathrm{RF}$ & rPTH, rTSH & c.112delC \\
\hline A7 & $\mathrm{F}$ & 5.8 & $\mathrm{BR}^{*}$, SS (6.8), OB/OW, RF & rPTH, rTSH & c. $1177 \mathrm{G}>\mathrm{T}$ \\
\hline A8 & $\mathrm{F}$ & 7.19 & BR, SO (13), OB/OW (10.7), RF & rPTH, rTSH & c.348C > T \\
\hline A9 & M & 23.17 & $\mathrm{BR}, \mathrm{MR}$, SS & rTSH, rFSH/LH & c. $478 \mathrm{G}>\mathrm{A}$ \\
\hline $\mathrm{A} 10$ & $\mathrm{~F}$ & 0.95 & $\mathrm{SO}, \mathrm{OB}, \mathrm{RF}$ & rPTH, rTSH & c. $1009 C>T$ \\
\hline A11 & M & 8.2 & $\mathrm{BR}, \mathrm{SO}, \mathrm{MR}, \mathrm{SS}, \mathrm{RF}$ & rPTH, rTSH, rFSH/LH & c. $103 C>T$ \\
\hline $\mathrm{A} 12$ & $\mathrm{~F}$ & 12.73 & $\mathrm{BR}, \mathrm{OB} / \mathrm{OW}, \mathrm{RF}$ & rPTH, rTSH & c. $1177 \mathrm{G}>\mathrm{T}$ \\
\hline $\mathrm{A} 13$ & M & 12.72 & $\mathrm{SS}, \mathrm{RF}$ & rPTH, rTSH & c. $1177 \mathrm{G}>\mathrm{T}$ \\
\hline A14 & $\mathrm{F}$ & 4.45 & $\mathrm{BR}, \mathrm{SO}, \mathrm{MR}, \mathrm{RF}$ & rPTH, rTSH, rFSH/LH & c.523_524del \\
\hline A15 & M & 4.45 & $\mathrm{BR}, \mathrm{SO}, \mathrm{MR}, \mathrm{SS}, \mathrm{OB} / \mathrm{OW}, \mathrm{RF}$ & rPTH, rTSH & c.523_524del \\
\hline A16 & M & 6.2 & $\mathrm{SO}, \mathrm{MR}$ & rPTH, rTSH & c. $212+2 \_212+6 \mathrm{del}$ \\
\hline A17 & $\mathrm{F}$ & 2 & BR (10.3), SO, (OB) & rPTH, rTSH, rGHRH (10.3) & c. $103 C>T$ \\
\hline A18 & $\mathrm{F}$ & 23.41 & $\mathrm{BR}, \mathrm{SO}, \mathrm{MR}, \mathrm{OB}, \mathrm{RF}$ & rPTH, rTSH & c. $103 C>T$ \\
\hline A19 & $\mathrm{F}$ & 7.2 & $\mathrm{BR}$ & rPTH, rTSH & c. $742 \mathrm{G}>\mathrm{C}$ \\
\hline $\mathrm{A} 20$ & $\mathrm{~F}$ & 10.47 & $\mathrm{BR}, \mathrm{OB} / \mathrm{OW}$ & rPTH, rTSH & c. $742 \mathrm{G}>\mathrm{C}$ \\
\hline A21 & M & 11.01 & $\mathrm{BR}, \mathrm{SS}, \mathrm{OB}, \mathrm{RF}$ & rPTH, rTSH, rLH/FSH & c. $1009 C>T$ \\
\hline $\mathrm{A} 22$ & M & 2 & $\mathbf{B R}^{*}$ (8), SO, MR, OB (0.5), RF(11) & rTSH, rPTH (8) & c.521_522del \\
\hline A23 & M & 11.23 & $\mathrm{BR}, \mathrm{MR}, \mathrm{OB} / \mathrm{OW}, \mathrm{RF}$ & rPTH, rTSH & C. $805 A>G$ \\
\hline A24 & M & 10.1 & $\mathrm{BR}, \mathrm{SO}, \mathrm{MR}, \mathrm{RF}$ & rPTH, rTSH & c.568_571del \\
\hline A25 & $\mathrm{F}$ & 9.75 & $\mathrm{BR}, \mathrm{MR}, \mathrm{SS}, \mathrm{OB} / \mathrm{OW}, \mathrm{RF}$ & rPTH, rTSH, rFSH/LH rlns & c.91C > T \\
\hline A26 & $\mathrm{F}$ & 1.5 & $\mathrm{BR}, \mathrm{SO}, \mathrm{MR}, \mathrm{OB}, \mathrm{RF}$ & rPTH, rTSH, rlns & C.91C > T \\
\hline A27 & $\mathrm{F}$ & 1.5 & $\mathrm{SO}, \mathrm{RF}$ & rPTH, rTSH & c.568_571del \\
\hline A28 & $\mathrm{F}$ & 4.6 & $\mathrm{BR}, \mathrm{SO}, \mathrm{MR}, \mathrm{SS}, \mathrm{OB} / \mathrm{OW}, \mathrm{RF}$ & rPTH, rTSH & c.568_571del \\
\hline A29 & M & 1.3 & $\mathrm{MR}, \mathrm{OB}, \mathrm{RF}$ & rPTH, rTSH & c.568_571del \\
\hline $\mathrm{A} 30$ & M & 1.3 & $\mathrm{BR}, \mathrm{MR}$ (2.8), SS, (OB), RF & rPTH (2.8), rTSH, rGHRH & c.21dupT \\
\hline A31 & $\mathrm{F}$ & 1.54 & $\mathrm{SO}, \mathrm{MR}, \mathrm{OB} / \mathrm{OW}, \mathrm{RF}$ & rTSH (1.9), rPTH (4) & c.347_348insT \\
\hline A32 & $\mathrm{F}$ & 8.86 & $\mathrm{BR}, \mathrm{MR}, \mathrm{OB}, \mathrm{RF}$ & rPTH, rTSH & c. $481 C>T$ \\
\hline A33 & $\mathrm{F}$ & 8.43 & $\mathrm{BR}, \mathrm{MR}, \mathrm{RF}$ & rPTH, rTSH & c.568_571del \\
\hline A34 & $\mathrm{F}$ & 14 & $\mathrm{BR}, \mathrm{MR}, \mathrm{SS}, \mathrm{OB} / \mathrm{OW}, \mathrm{RF}$ & rPTH, rTSH & c. $728 \mathrm{C}>\mathrm{T}$ \\
\hline A35 & M & 12.77 & $\mathrm{BR}, \mathrm{SO}$ & rPTH, rTSH & c.110del \\
\hline A36 & $\mathrm{F}$ & 16.8 & $\mathrm{BR}, \mathrm{SO}, \mathrm{MR}, \mathrm{OB} / \mathrm{OW}, \mathrm{RF}$ & rPTH, rTSH & c.1021_1022ins23nt \\
\hline A37 & $\mathrm{F}$ & 4.89 & $\mathrm{BR}^{*}, \mathrm{MR}, \mathrm{OB}, \mathrm{RF}$ & rPTH, rTSH & c.863_864del \\
\hline A38 & $\mathrm{F}$ & 3.56 & $\mathrm{BR}, \mathrm{SO}, \mathrm{SS}, \mathrm{OB} / \mathrm{OW}, \mathrm{FR}$ & rPTH, rTSH & c.87dupA \\
\hline A39 & $\mathrm{F}$ & 0.1 & $\mathrm{BR}, \mathrm{SO}, \mathrm{MR}$, (OB 0.1), RF & rPTH, rTSH, & c.568_571del \\
\hline $\mathrm{A} 40$ & $\mathrm{~F}$ & 0.94 & $\mathrm{BR}^{*}, \mathrm{SS},(\mathrm{OB} / \mathrm{OW}), \mathrm{RF}$ & rPTH & c. $1177 \mathrm{G}>\mathrm{A}$ \\
\hline A41 & M & 2.32 & $\mathrm{BR}, \mathrm{SO}, \mathrm{OB} / \mathrm{OW}, \mathrm{RF}$ & rPTH, & c.347_348insC \\
\hline A42 & $\mathrm{F}$ & 13.86 & $\mathrm{BR}, \mathrm{MR}, \mathrm{RF}$ & rTSH & c.97G $>$ A \\
\hline A43 & $\mathrm{F}$ & 0.91 & $\mathrm{BR}, \mathrm{MR}, \mathrm{SS}, \mathrm{OB}, \mathrm{RF}$ & rPTH, rTSH & c.363_364del \\
\hline
\end{tabular}


Table 2 Clinical features and molecular characterization of patients with GNAS gene mutations (Continued)

\begin{tabular}{llllll}
\hline A44 & F & 14.38 & BR, SS & - & c.568_571del \\
A45 & $M$ & 14.15 & BR, SO & rPTH & c.103C > T \\
A46 & M & 6.61 & SO, OB/OW (9.11) & rPTH & c.103C > T \\
\hline
\end{tabular}

Features that occurred prior to the first diagnosis or later in life are remarked in bulk and the corresponding age is noticed in parenthesis. Features that were present at the diagnosis but disappeared later in life are reported in parenthesis. A12 + A13; A14 + A15; A19 + A20; A25 + A26; A45 + A46 are couple of brothers and/or sisters

directly sequenceed by using the ABI PRISM ${ }^{\bullet}$ Genetic Analyzer 3100 (Applied Biosystems, Foster City, CA). Each mutation has been searched for and excluded in 50 control subjects as previously described [16]. For few mutations in vitro mutant expression has been tested [6].

\section{Methylation analysis of GNAS locus and detection of STX deletions}

GNAS DMRs methylation status was assessed both by combined bisulfite restriction analysis and methylation specific-multiplex ligand-dependent probe amplification (MS-MLPA). The presence of STX16 gene deletions was

Table 3 Clinical features and molecular characterization of patients with GNAS locus altered methylation

\begin{tabular}{|c|c|c|c|c|c|}
\hline$\overline{\text { Case }}$ & Sex & Age & $\mathrm{AHO}$ signs & Hormone resistances & GNAS locus methylation alteration \\
\hline B1 & M & 6.9 & $\mathrm{BR}, \mathrm{MR}, \mathrm{RF}$ & rPTH, rTSH (11) & AB/NESP/AS/XL \\
\hline B2 & M & 11.43 & MR (3.5), RF & rPTH & AB/NESP/AS/XL \\
\hline B3 & $\mathrm{F}$ & 7.5 & - & rPTH & AB/NESP/AS/XL \\
\hline B4 & $\mathrm{F}$ & 65 & $\mathrm{BR}, \mathrm{OB}, \mathrm{RF}$ & rPTH, rLH/FSH & AB/NESP/AS/XL \\
\hline B5 & $\mathrm{F}$ & 5.2 & $\mathrm{MR}, \mathrm{OB} / \mathrm{OW}, \mathrm{RF}$ & rPTH, rTSH & AB/NESP/AS/XL \\
\hline B6 & $\mathrm{F}$ & 9.95 & RF & rPTH & AB/NESP/AS/XL \\
\hline B7 & M & 15 & $\mathrm{BR}$ & rPTH & $\mathrm{AB} / \mathrm{NESP} / \mathrm{AS} / \mathrm{XL}$ \\
\hline B8 & $\mathrm{F}$ & 13.26 & - & rPTH & AB/NESP/AS/XL \\
\hline B9 & M & 12.13 & - & rPTH & AB/NESP/AS/XL \\
\hline B10 & $F$ & 6.55 & $\mathrm{MR}, \mathrm{OB} / \mathrm{OW}$ & rPTH, rTSH & AB/NESP/AS/XL \\
\hline B11 & M & 10.5 & $\mathrm{BR}, \mathrm{OB} / \mathrm{OW}, \mathrm{RF}$ & rPTH & AB/NESP/AS/XL \\
\hline B12 & M & 37.5 & $\mathrm{BR}, \mathrm{SS}, \mathrm{OB} / \mathrm{OW}, \mathrm{RF}$ & rPTH & AB/NESP/AS/XL \\
\hline B13 & $\mathrm{F}$ & 9 & RF & rPTH & AB/NESP/AS/XL \\
\hline B14 & $\mathrm{F}$ & 0.5 & OB/OW, RF & rPTH, rTSH & AB/NESP/AS/XL \\
\hline B15 & M & 12.76 & RF & rPTH & AB/NESP/AS/XL \\
\hline B16 & M & 12.23 & BR & rPTH & AB/NESP/AS/XL \\
\hline B17 & M & 12 & $\mathrm{BR}, \mathrm{OB}, \mathrm{RF}$ & rPTH, rTSH & AB/NESP/AS/XL \\
\hline B18 & M & 16 & $\mathrm{BR}^{*}, \mathrm{OB} / \mathrm{OW}, \mathrm{RF}$ & rPTH, rGHRH & AB/NESP/AS/XL \\
\hline B19 & $\mathrm{F}$ & 4 & $\mathrm{BR}^{*}, \mathrm{OB} / \mathrm{OW}, \mathrm{RF}$ & rPTH, rTSH & AB/NESP/AS/XL \\
\hline B20 & $\mathrm{F}$ & 4.16 & $\mathrm{MR}, \mathrm{OB} / \mathrm{OW}, \mathrm{RF}$ & rPTH, rTSH & AB/NESP/AS/XL \\
\hline B21 & $F$ & 10.09 & RF & rPTH, rTSH & AB/NESP/AS/XL \\
\hline B22 & F & 7,41 & $\mathrm{BR}$ & rPTH & AB/NESP/AS/XL \\
\hline B23 & $F$ & 5.5 & $\mathrm{BR}, \mathrm{MR}, \mathrm{RF}$ & rPTH & AB/NESP/AS/XL \\
\hline B24 & $\mathrm{F}$ & 23.5 & $\mathrm{BR}, \mathrm{MR}$ & rPTH & AB/NESP/AS/XL \\
\hline B25 & $F$ & 3.06 & BR & rPTH, rTSH (6) & AB/NESP/AS/XL \\
\hline B26 & M & 29 & $\mathrm{BR}^{*}, \mathrm{OB} / \mathrm{OW}$ & rPTH & Del at STX16 gene \\
\hline B27 & M & 12.9 & - & rPTH & Del at STX16 gene \\
\hline B28 & $\mathrm{F}$ & 19.6 & $\mathrm{SS}, \mathrm{OB} / \mathrm{OW}, \mathrm{RF}$ & rPTH & Del at STX16 gene \\
\hline
\end{tabular}

Sex: Female (F), Male (M); Age: age at diagnosis or at first evaluation, expressed in years; AHO signs: brachydactyly (BR, in case of X-Ray study: BR*), subcutaneous ossifications (SO), mental retardation (MR), short stature (SS), obesity and overweight (OB/OW), round face (RF); Hormone resistances: PTH resistance (rPTH), TSH resistance $(\mathrm{rTSH}), \mathrm{FSH} / \mathrm{LH}$ resistance $(\mathrm{rFSH} / \mathrm{LH}), \mathrm{GHRH}$ resistance $(\mathrm{rGHRH})$, Insulin resistance (rlns). Features that occurred prior to the first diagnosis or later in life are remarked in bulk and the corresponding age is noticed in parenthesis. Features that were present at the diagnosis but disappeared later in life are reported in parenthesis. $A 12+A 13 ; A 14+A 15 ; A 19+A 20 ; A 25+A 26 ; A 45+A 46$ are couple of brothers and/or sisters 
investigated by multiplex PCR and MS-MLPA, as previously described $[8,16,24]$.

\section{Statistical analysis}

To explore the relationship among clinical features and molecular diagnosis we used the Mann-Whitney $U$ and Fisher nonparametric tests, available as open access tools on the VassarStats: Website for Statistical Computation (http://vassarstats.net). A two-tailed $P$ value of $<0.05$ was considered statistically significant and results are presented as median value and range.

\section{Results}

The two groups of patients differ in the age of onset of the disease $(p<0.001)$ : patients with genetic mutations came to medical attention at a median age of 4.8 years (range 0.1-23.4) and in 29/46 cases (63\%) the reasons for consultation were AHO signs (early-onset obesity, delayed growth, heterotopic ossifications) and/or hormonal alterations (overall hypothyroidism); 4/46 patients only showed symptomatic hypocalcaemia as first sign. Conversely, patients with locus alterations were older at diagnosis (median age 10.5 years; range $0.5-65$ ), most of them $(n=20 / 28,70 \%)$ presenting with seizures, tetany, and positive Trousseau's sign.

Clinical data prevalence in the studied series is resumed in Fig. 1: PTH resistance was detected in most patients with genetic mutations $(n=43 / 46,93 \%)$ at a median age of 5 years (range 0.9-23.4), while all patients with imprinting alterations showed $\mathrm{rPTH}$ at diagnosis, often occurring later in life (median age 11.6 years; range 0.5- 65), with symptomatic hypocalcaemia. TSH resistance arose in $43 /$ 46 patients (93\%) with genetic mutations at median age of 5.8 years (range $0.25-23.4$ ) and in $9 / 28$ patients (32\%) with imprinting alterations at median age of 6.28 years (range 0.5-11).
Other hormone resistances were reported in $8 / 46$ patients with genetic mutations (17\%) only, but notably 44 of the total case series were younger than 12 years at the time of last evaluation. Gonadotropins resistance was recorded in 5 patients, associated to insulin resistance in one of them (A26), which is the further isolated hormonal resistance in her sister (A25). GH defect was detected at diagnosis in 2 patients: A30 (1.3 and 5 years old at diagnosis and follow-up, respectively) showed short stature and a lack of response to the GHRH + Arginine test but a second test was not performed because his height velocity (HV) has improved; and A17 (2 and 10.3 years old at diagnosis and follow-up, respectively), displayed GH deficiency after two stimulation tests. Therefore she underwent a treatment with hrGH with $\mathrm{HV}$ improvement and normalization of the height to target height.

Among patients with epimutations, in one patient (B18) only GHRH resistance has been reported, occurring in adult age; for a female patient (B4) hypofertility was referred when she was 29 , but she came late to medical observation with incidental diagnosis of hypocalcaemia as possible sign of mild hormonal alteration.

Auxological evaluations were obtained (Fig. 2) in 44/46 patients with genetic mutations and SS became evident in 15 subjects $(34 \%)$ at a median age of 6.8 years (range 0.91-23.17); 11 of them were still pre-pubertal at the time of the examination $(<12$ years). Auxological data were available for $23 / 28$ subjects with imprinting alterations and 2 of them (9\%) were short at the time of enrollment.

Weight excess was recorded in 32/44 patients with genetic mutations (73\%) and it encompassed either early-onset obesity $(n=19,43 \%)$ with a median age of 1.5 years (range $0.9-23.4)$, or overweight $(n=13,30 \%)$ later (median age 10.1 years, range $1.5-19.5)$. Most patients $(n=28)$ with weight excess were pre-pubertal $(<12$ years $)$ at the time of the evaluation. Only $2 / 23$ subjects with imprinting alterations (9\%) showed overt obesity at extremely different

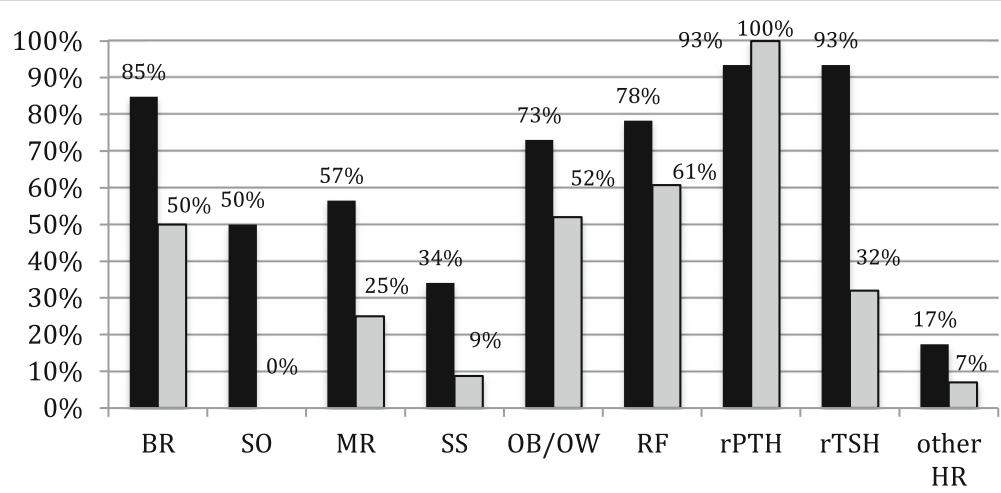

Fig. 1 Prevalence of AHO signs and hormone resistances in the 2 group of patients with GNAS gene mutations (dark grey bars) and GNAS locus mutations (light grey bars): encompassing brachydactyly (BR) ( $p$-value 0.002), subcutaneous ossifications (SO), mental retardation (MR) ( $p$ value $0.008)$, short stature (SS) ( $p$ value 0.04$)$, obesity and overweight (OB/OW) ( $p$ value 0.16$)$, round face (RF) ( $p$ value 0.18$)$, PTH resistance (rPTH), TSH resistance $(r T S H)$ ( $p$ value $<0.0001$ ), other hormone resistances (HR) ( $p$ value 0.37 ) 


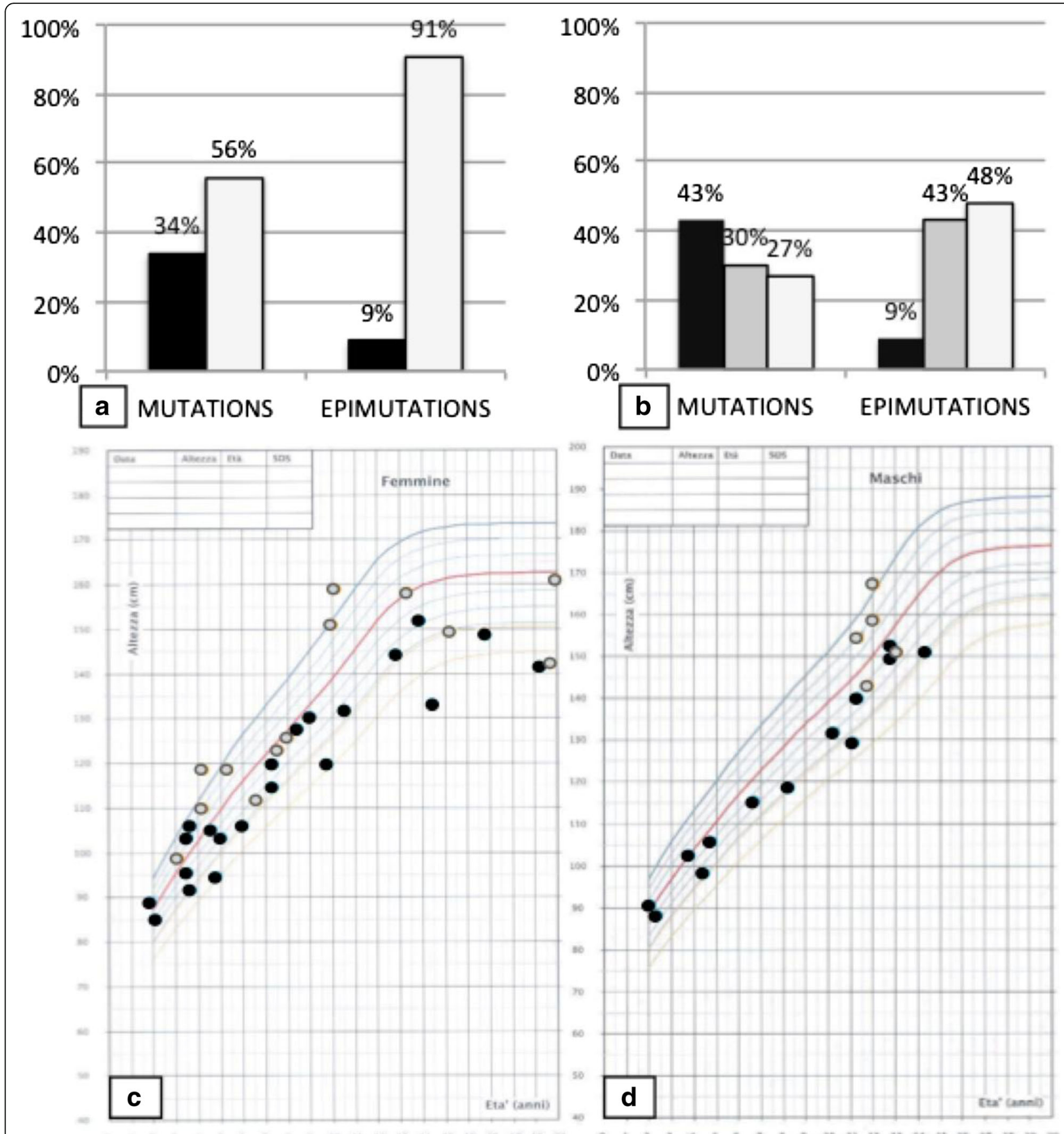

Fig. 2 a Prevalence of short (black bars) compared to normal stature (white bars), between the 2 groups of patients with GNAS gene mutations (named "Mutations") and GNAS locus imprinting alterations (named "Epimutations"). b Prevalence of weight excess (overt obesity: black; overweight: grey) compared to normal weight (white) at the time of enrollment between two groups with GNAS gene mutations (named "Mutations") anf GNAS locus imprinting alterations (named "Epimutations"). $\mathbf{c}$ and $\mathbf{d}$ : Heights of the presented case series at the time of enrollment on females (section $\mathbf{c}$ ) and males growth chart (section $\mathbf{d}$ ); patients with GNAS gene mutations are presented by blue plots and those with GNAS locus imprinting alterations by yellow plots

ages (1.2 and 65 years); while 10/23 further patients (43\%) were overweight (median age 14.4 years, range 4.2-37.5).

Follow-up data in 13 patients with genetic mutations (Fig. 3) demonstrated an evolution of the auxological parameters over the time: during a mean follow-up time of 6.2 years, SS prevalence increased from 31\% (median age 1.4 years, range $0.94-8.2$ ) to $38 \%$ (median age 10.1 years, range 5.04-17.1), while weight excess prevalence decreased 


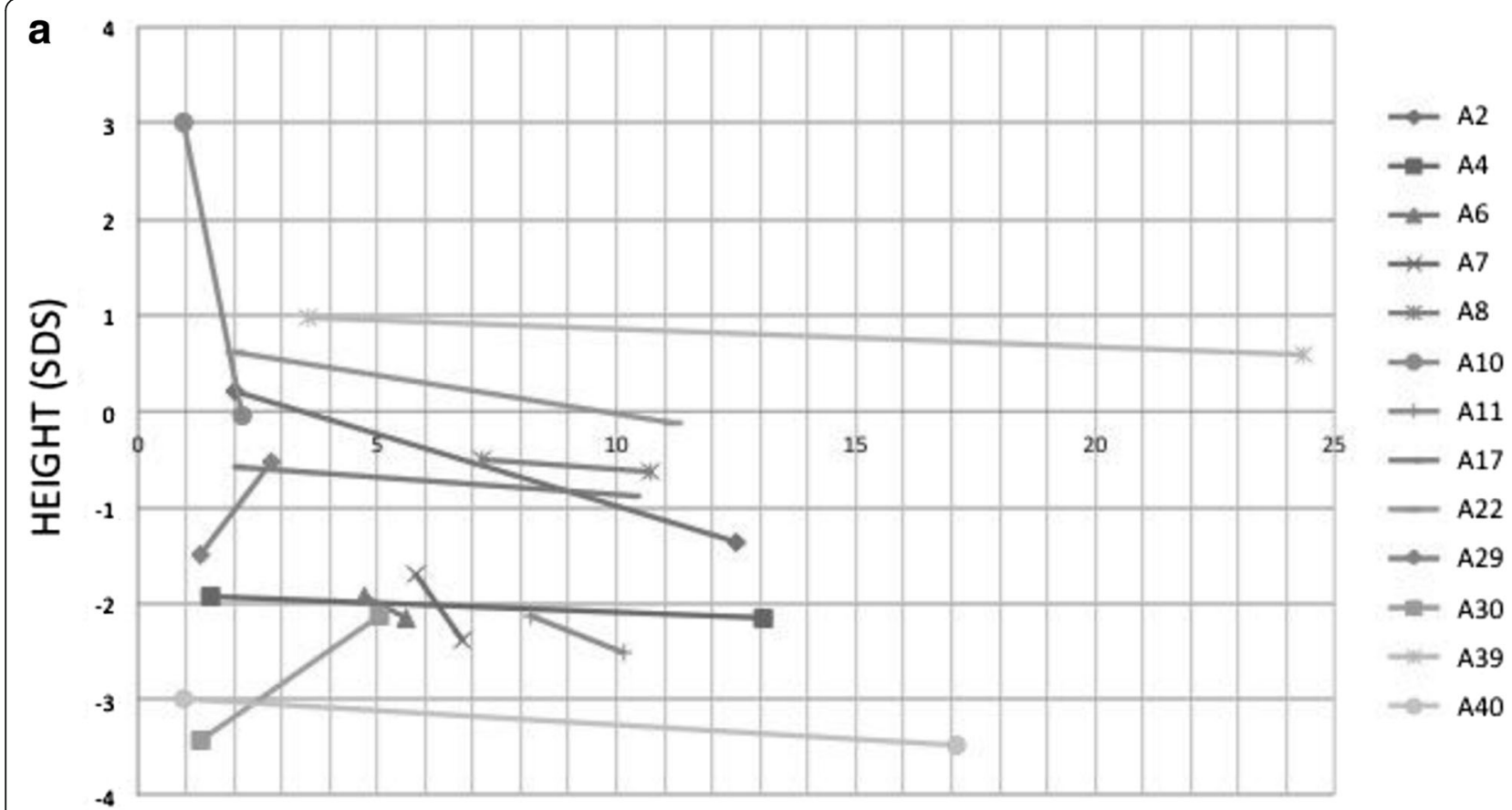

AGE (YEARS)

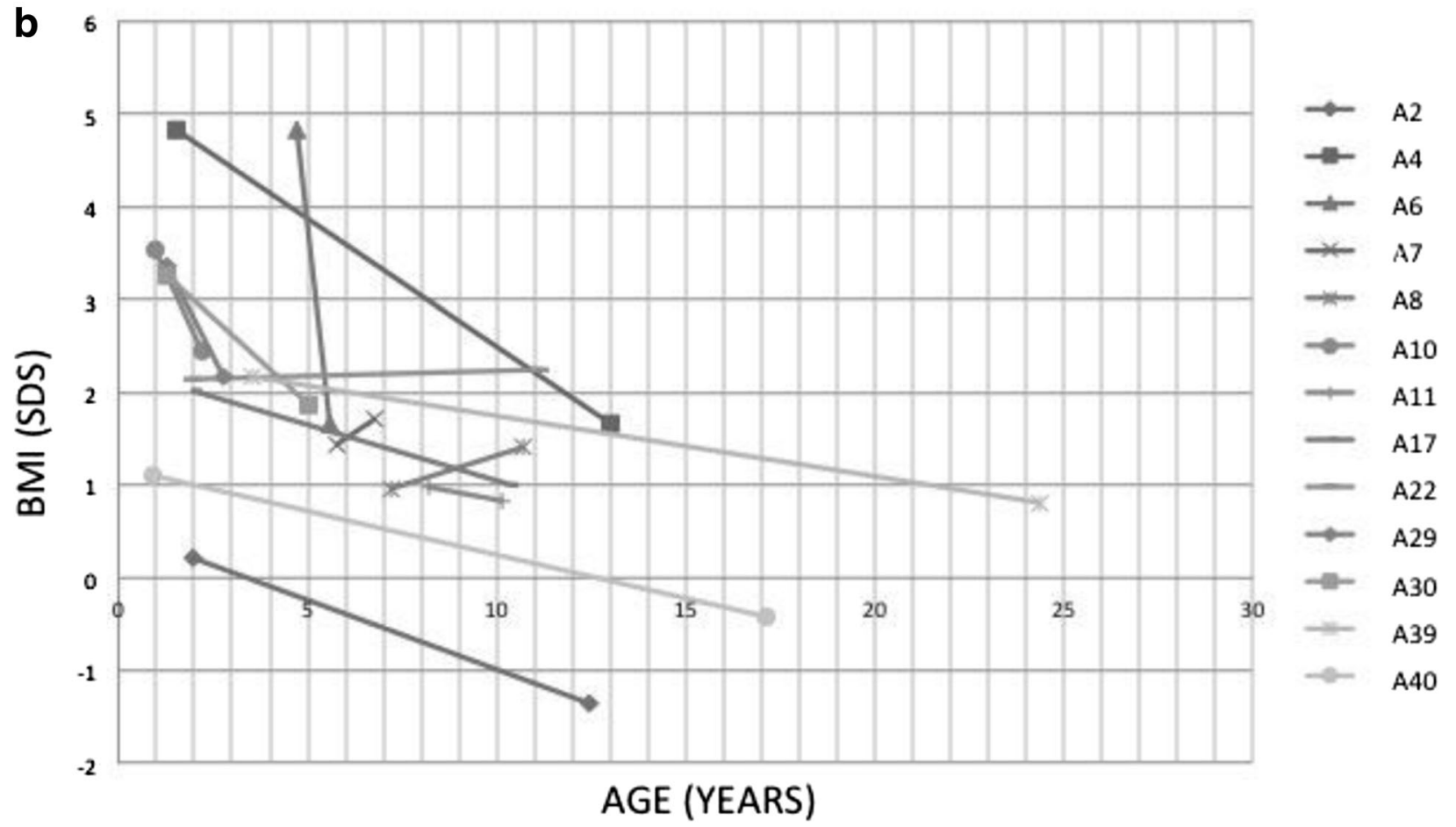

Fig. 3 Height (plot a) and Weight (plot b) auxological data of 13 patients with GNAS gene mutations at follow-up: data are presented as Standars Deviation Score (SDS) calculated on age-adapted growth charts vs. age in years (AGES)

from 77 to $54 \%$. At the time of enrollment 10 very young patients (oldest age 5.8 years) showed weight excess: at follow-up half of them normalized or strongly reduced the weight at a median age of 12.5 years (range 5.6-
24.35), while the remaining 5 patients were still obese or overweight (median age 5.0 years, range 2.2-11.2). For all patients, hypocaloric regimens for age and recommendations aimed to increase the physical activity 
over the time were the only reported therapeutic approaches, without clarification about any further specific treatment.

BR has been identified in 39/46 subjects with genetic mutations (85\%) at a median age of 7.2 years (range 0.9 23.4 ), while the sign was positive in $14 / 28$ subjects with imprinting alterations $(50 \%, p=0.002)$ and recorded at a later median age of 13.2 years (range $1.2-65 ; p<0.001$ ). None of the latter showed SO, which were detected in $23 / 46$ subjects harboring genetic mutations $(50 \%)$, at a median age of 4.5 years (range 1.5-23.4). Interestingly, 9/11 (82\%) patients with exon 1 mutations showed SO, which were present in 14/35 (40\%) patients only harboring mutations throughout the remaining GNAS coding region. Signs of MR were more often observed among mutated than epimutated patients (in 26 and 7 patients respectively, 57 and $25 \%, p=0.008$ ), but the age at presentation didn't show any statistical difference (median age was 4.75 years in both groups). Few information were available about the features of the cognitive impairment: among patients with genetic mutations it involved psychomotor $(n=4)$ or speech delay $(n=4)$, school problems with need of extra help $(n=2)$, and a slight global retardation of developmental milestones $(n=5)$; results of objective cognitive tests were available for 5 patients.

The review and update of clinical data of this countrywide collected cohort of patients with confirmed molecular diagnosis of PHP has led us to develop two flowcharts, one for the initial diagnosis and the other for the monitoring of the disease, as common tool for the clinical routine management of these subjects (Fig. 4).

\section{Discussion}

The present study reports the clinical review and update about the largest cohort of patients with a confirmed molecular diagnosis of PHP, in order to propose a common standard of care. Due to the rarity of the disease and to the overlapping phenotype among patients with different genotypes we think that initially it may be more useful to organize the clinical management and followup of PHP patients in a unique scheme, independently of their genotype. This approach will possibly help in detecting (and treating) clinical features earlier during the history of the disease. The adoption of a common healthcare pathway will allow the collection of standardized data that may improve the further characterization of the disease, including more precise information about the phenotype/genotype correlation, and the success of treatments.

Similar to previous reports $[25,26]$ our patients showed a bimodal way of presentation: younger pediatric subjects seeking for medical advice because of earlyonset obesity and/or congenital hypothyroidism had more often structural gene mutations, suggesting a more severe impairment of the Gs $\alpha$ protein, not only in endocrine organs as reported by prior functional studies [27], but probably also in adipose tissue. Conversely, symptomatic hypocalcaemia is the most often presentation in peripubertal and older patients harboring locus imprinting alterations: this genotype might induce a slight impairment of the Gs $\alpha$ activity which, thank to a higher production of PTH, would preserve normocalcaemia until puberty or even adulthood, when the increased calcium requirement makes the resistance clinically evident. As regard to $\mathrm{rPTH}$ it is nowadays debated how long-term elevated PTH and calcium substitution might interfere on bone health status and BMD [28]: a focused monitoring of calcium/phosphorus metabolism and mineral bone status, also considering the different treatment regimens adopted over the time, might produce more uniform data to gain some new insight into these issues for patients with both genotypes.

Often described as subclinical hypothyroidism [22], rTSH was confirmed as the second most common hormone derangement $[29,30]$. Its congenital or early onset in patients with either genetic or epigenetic mutations suggests that it should be searched for at diagnosis in both PHP subtypes; furthermore this finding seems to indicate a greater sensitivity to the Gs $\alpha$ altered pathway in thyroid than in parathyroid cells [26]. In order to define common clinical approaches, standardized followup studies are required to assess the optimal TSH-cutoff (TSH $5-10 \mu \mathrm{U} / \mathrm{ml}$ ) at which substitutive treatment should be started, its duration until or after the growth has been completed and the timing of TSH levels monitoring.

Although multiple hormone resistances were classically described in PHP-Ia patients [1], their relative low prevalence in our series could in part be explained by the very young age of most subjects, but it also might reflect that neither the historically reported hormonal derangements (involving vasopressin, prolactin, ACTH, CRF, calcitonin and glucagon [31-33]) nor the newly recognized ones (including insulin, leptin and $\alpha \mathrm{MSH}$ [5]) are initially investigated and routinely included in the follow-up program. Likewise for rGHRH, reported as a common finding in PHP-Ia subjects, the GH secretory testing should be part of the initial management [22, 34]. A prompt diagnosis of GH deficiency as soon as height velocity decreases, would allow an early replacement treatment overall before the typically observed premature fusion of growth plates hampers the pubertal growth spurt. Controlled trials enrolling large series of genetically and clinically characterized PHP-Ia subjects would be necessary to clarify the correct rhGH dosage, the duration of treatment and the eventual combination with GnRH analogs [35]. 


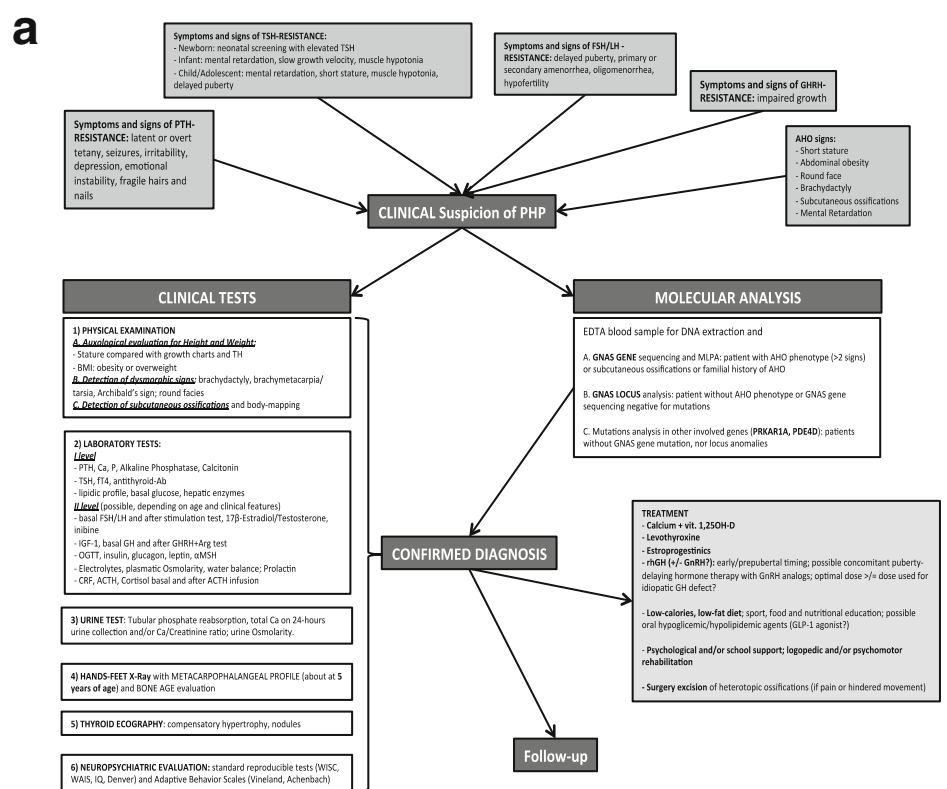

b

\begin{tabular}{|c|c|c|}
\hline PHP FEATURES & MONITORING (onset/persistence) & THERAPY \\
\hline PTH-resistance & $\begin{array}{l}\text { - Laboratory tests (every } 6 \text { months) } \\
\text { PTH, Ca, P, Alkaline Phosphatase, Creatinine } \\
\text { (yearly) Calcitonin } \\
\text { - Urine test (every } 6 \text { months) } \\
\text { Calciuria on } 24 \text {-hours urine collection, } \\
\text { Ca/Creatinine ratio, Tubular phosphate } \\
\text { reabsorption } \\
\text { - Renal-bladder ultrasound (yearly, before if } \\
\text { changed treatment) } \\
\text { - Bone Mineral Density (yearly or every two } \\
\text { years, depending on } \mathrm{Ca} / \mathrm{P} \text { balance ) }\end{array}$ & $\begin{array}{l}\text { Calcium + vit. D metabolites } \\
\text { Dose optimization in adolescents, } \\
\text { especially in case of intense exercise } \\
\text { training }\end{array}$ \\
\hline TSH-resistance & $\begin{array}{l}\text { - Laboratory tests (every } 6 \text { months) } \\
\text { TSH, fT4 } \\
\text { - Thyroid ultrasound (once, or yearly in case } \\
\text { of laboratory tests alterations) } \\
\text { Evaluate the presence of thyroid nodules } \\
\text { (incidence and prevalence) }\end{array}$ & $\begin{array}{l}\text { Levothyroxine } \\
\text { Eventual stop treatment in case of: } \\
\text { - subclinical hypothyroidism } \\
\text { - complete growth, adulthood }\end{array}$ \\
\hline FSH/LH-resistance & $\begin{array}{l}\text { - Hormone levels (in case of menstrual cycle } \\
\text { irregularities) } \\
\text { FSH/LH, 17ß-Estradiol, Prolactin } \\
\text { - Pelvic ultrasound (in case of laboratory tests } \\
\text { alterations) }\end{array}$ & $\begin{array}{l}\text { Estroprogestinics- or } \\
\text { Testosterone-substitutive therapy }\end{array}$ \\
\hline GHRH-resistance & $\begin{array}{l}\text { - Auxology evaluation / growth velocity } \\
\text { (every } 6 \text { months) } \\
\text { - Bone age X-Ray (depending on growth) } \\
\text { - Laboratory tests: } \\
\text { IGF-1, then GH basal and after GHRH+Arg } \\
\text { test }\end{array}$ & $\begin{array}{l}\text { rhGH +/- GnRH analogs } \\
\text { - Dose optimization on IGF-1 levels } \\
\text { - Evaluate best timing/duration } \\
\text { (reaching adult stature/TH) } \\
\text { - Consider treatment in adulthood }\end{array}$ \\
\hline $\begin{array}{r}\text { Other Hormones } \\
\text { resistance }\end{array}$ & $\begin{array}{l}\text { - Laboratory tests (yearly) } \\
\text { ACTH, Cortisol basal and after exogenous } \\
\text { ACTH infusion }\end{array}$ & Hormone substitutive therapy \\
\hline Obesity & $\begin{array}{l}\text { - Auxological Evaluation } \\
\text { Ilevel tests: (every } 6 \text { months) } \\
\text { lipidic profile, basal glucose, glycosylated } \mathrm{Hb}, \\
\text { liver enzymes } \\
\text { I level (in case of I level laboratory tests } \\
\text { alterations) OGTT, insulin, glucagon }\end{array}$ & $\begin{array}{l}\text { - Diet } \\
\text { - Physical activity } \\
\text { - Pharmacological approach? }\end{array}$ \\
\hline Brachydactyly & $\begin{array}{l}\text { - Hands/feet X-Ray with } \\
\text { metacarpophalangeal profile (once at } \\
\text { diagnosis; repeat at } 5 \text { th year in case of PHP } \\
\text { was diagnosed earlier; then repeat only in case } \\
\text { of clinical evidence of BR appearance) }\end{array}$ & \\
\hline Mental Retardation & $\begin{array}{l}\text { - Neuropsychiatric Evaluation (yearly) } \\
\text { of psychomotor and neurocognitive evolution }\end{array}$ & $\begin{array}{l}\text { Rehabilitation } \\
\text { (psychological / school/ } \\
\text { employment support) }\end{array}$ \\
\hline $\begin{array}{r}\text { Subcutaneous } \\
\text { Ossifications }\end{array}$ & $\begin{array}{l}\text { - Physical examination and body-mapping } \\
\text { (yearly) } \\
\text { Distinction between superficial and progressive } \\
\text { forms } \rightarrow \text { differential diagnosis with POH }\end{array}$ & $\begin{array}{l}\text { Surgery excision } \\
\text { in case of pain or hindered } \\
\text { movements }\end{array}$ \\
\hline
\end{tabular}

Fig. 4 (See legend on next page.) 
(See figure on previous page.)

Fig. 4 Diagnostic (a) and follow-up (b) flowcharts for patients with suspected PHP. a In the initial diagnostic phase we suggest to assess the presence or absence of each AHO sign and hormone resistance possibly involved in PHP through targeted clinical examinations (physical and neuropsychiatric), laboratory tests (on blood and urine) and medical imaging investigations. This wide diagnostic approach, despite laborious, represents an exhaustive base-line assessment for later comparative examinations. b During the follow-up management we propose for each clinical feature involved in PHP a practical checklist of clinical, biochemical and/or imaging investigations to perform periodically or in case of symptoms in the follow-up of PHP patients. In particular, we believe that patients who are very young at diagnosis would benefit of systematic reevaluations, in order to correctly manage late complications of the disease and to detect late-onset signs during the growth for a prompt treatment

The evidence of rGHRH in a patient with altered methylation further confirms [26] the possible onset of GH deficiency also in PHP-Ib subgroup of patients and indicates the need of more investigations to assess its prevalence and the correct management in this subtype.

As regards to the AHO signs, among patients with genetic mutations evolutive trends have been evidenced for both SS and OB: the increasing prevalence of SS over the time strengthen the need of a standardized early diagnosis and treatment not only of rGHRH but also of other hormonal derangements that may have an impact on the final stature of these subjects [35]. Conversely, early weight excess, overall $\mathrm{OB}$, supports the hypothesis that an abnormal function of the melanocortin-4 receptors, impairing energy expenditure and insulin sensitivity and inducing early hyperphagia $[5,36]$, might be responsible for fat accumulation since infancy. The fact that weight excess becomes milder might suggest that other factors influence the energy intake and expenditure, as well as the body composition over the time. The treatment of $\mathrm{OB}$ and $\mathrm{OW}$ in these patients has been so far limited to suggestions for a balanced nutrition and regular body-exercise; thus, the lack of common standards made the therapeutic approach often inhomogeneous. The inclusion of low-calories and low-fat dietary regimens, the indication of regular physical activity over the time and the development of nutritional education programs as part of the therapeutic approach in these patients and their families will probably help in reducing their metabolic impairment. The feasibility of physical pharmacological treatment to reduce the caloric intake may be evaluated as alternative if dietary approach is unsuccessfully. The possibility to share standardized data searching for insulin resistance in large series would also indicate the correct follow-up and a specific therapeutic approach in those subjects with hormonal derangement. Furthermore, it is important to stress that $\mathrm{OB}$ and OW may be related to hormonal impairments but also to a different eating behavior, overall during the evolutive age: standardized endocrinological and psychological follow-up should help clarifying which of them might impact more on fat accumulation.

In this regard, data on mental retardation are still limited; our study further confirms the heterogeneity of the cognitive areas involved in the delay [22] and underlines the need of objective standard tests to verify the most involved areas, also recording the possible evolution of the retardation over the time. Parallel to the evaluation of the straight cognitive impairment, the recent approach to pediatric MR should include standard tests assessing coping skills and adaptive behaviors, which play a central role in how the delay impacts on the daily and social life of the patients [37, 38]. The presence of the sign also in a substantial fraction of patients with imprinting alterations may suggest that even mild reduction in Gsa function, might interfere with the neuronal activity affecting the normal development milestones.

BR is one of the most typical sign of PHP-Ia; its prevalence lower than $100 \%$ among subjects with genetic mutations may be explained by their young age (below to the indicated cut-off age of 5 years [39]), and also by the fact that the MPP hasn't been performed in all subjects, thus potentially underdiagnosing the milder bone alterations. The new prevalence data of $50 \%$ among epimutated patients, raises the question if even a slight reduction in Gs $\alpha$ activity might produce specific alterations in hand bone growth: comparative studies are needed to define if it involves the same pattern as in mutated patients.

The only alterations that seem to be specific for genetic mutations are $\mathrm{SO}$, since our series confirms their complete absence in case of locus anomalies [26]. The higher percentage of exon 1 and frameshift mutations among patients showing SO might prove its pathogenetic role as unique one encoding exclusively for $G s \alpha$ [8]. The young median age of presentation and recent reports indicating possible progression patterns suggests to monitor their evolution in number, size and depth with systematic body-mapping during the follow-up, also in order to differentiate this sign from $\mathrm{POH}$.

\section{Conclusions}

In conclusion, PHP is indeed a very heterogeneous disease, deeply investigated at molecular level in the last decade, for which several clinical aspects have still to be defined in details. Facing its rarity and complexity the ISPED's Study Group developed the two flow-charts presented in the present paper as 
diagnostic and therapeutic tool for clinical routine purpose. The proposed pathways should certainly be validated on a larger cohort before their publication as official suggestions or guidelines, but meanwhile, they may be used as standardized schemes in order to obtain uniform clinical data for further studies in the PHP/AHO population.

\section{Acknowledgement}

Not applicable.

\section{Funding}

No funding.

\section{Availability of data and materials}

Reproducible materials described in the manuscript, including databases and all relevant raw data, are freely available to any scientist wishing to use them.

\section{Authors' contributions \\ LdS conceived the study, coordinated the data collection and the analysis of the GNAS gene and drafted the manuscript. FG participated in the data collection and in writing the draft of the manuscript. GM participated in the design of the study and coordinated the locus methylation analysis. MFE carried out the GNAS locus methylation analysis. GW, MS, GIB, PM, MW, and LM clinically followed the patients and collected the data. GS clinically followed the patients, collected the data and contributed to draft the manuscript. DT participated in the design of the study, in its coordination and helped to draft the manuscript. All authors read and approved the final manuscript.}

\section{Competing interests}

The authors declare that they have no competing interests.

\section{Consent for publication}

Not applicable.

\section{Ethics approval and consent to participate}

The informed consent was obtained from parents, after full explanation of the purpose and nature of all procedures used. A copy of the written consent is available for review by the Editor-in-Chief of this journal.

\section{Author details \\ 'Department of Public Health and Pediatric Sciences, University of Turin - Regina Margherita Children's Hospital - Health and Science City, Subintensiva Allargata Prima Infanzia, Piazza Polonia 94, 10126 Torino, Italy. ${ }_{2}^{2}$ Kinderklinik, Evangelisches Krankenhaus Oberhausen, Oberhausen, Germany. ${ }^{3}$ Fondazione IRCCS Ca' Granda Ospedale Maggiore Policlinico, Endocrinology Unit, Department of Clinical Sciences and Community Health, University of Milan, Milan, Italy. ${ }^{4}$ Department of Pediatrics, San Raffaele Hospital, University of Milan, Milan, Italy. ${ }^{5}$ Pediatric Endocrine Unit, Department of Translational Medical Sciences, University of Naples Federico II, Naples, Italy. ${ }^{6}$ Department of Obstetrics, Gynecology and Pediatrics, I Pediatric Division, University Hospital, Pisa, Italy. ${ }^{7}$ Pediatric Endocrinology and Diabetology Unit, Regina Margherita Children's Hospital - Health and Science City, Turin, Italy. ${ }^{8}$ Department of Pediatric, Gynecological, Microbiological and Biomedical Sciences, University of Messina, Messina, Italy. ${ }^{9}$ Pediatric Endocrinology and Rare Diseases, Department of Pediatrics, S.Orsola-Malpighi Hospital, University of Bologna, Bologna, Italy. ${ }^{10}$ Endocrinology Ward, Bambin Gesù Children's Hospital, Rome, Italy.}

Received: 13 August 2016 Accepted: 12 November 2016 Published online: 21 November 2016

\section{References}

1. Weinstein LS, Yu S, Warner DR, Liu J. Endocrine manifestations of stimulatory $\mathrm{G}$ protein alpha-subunit mutations and the role of genomic imprinting. Endocr Rev. 2001;22:675-705.

2. Mantovani G, Spada A. Mutations in the Gs alpha gene causing hormone resistance. Best Pract Res Clin Endocrinol Metab. 2006;20(4):501-13.
3. Thompson MD, Percy ME, McIntyre Burnham W, Cole DE. G protein-coupled receptors disrupted in human genetic disease. Methods Mol Biol. 2008;448: 109-37. doi:10.1007/978-1-59745-205-2_7.

4. Muniyappa R, Warren MA, Zhao X, Aney SC, Courville AB, Chen KY, et al. Reduced insulin sensitivity in adults with pseudohypoparathyroidism type 1a. J Clin Endocrinol Metab. 2013:98(11):E1796-801.

5. Shoemaker AH, Lomenick JP, Saville BR, Wang W, Buchowski MS, Cone RD. Energy expenditure in obese children with pseudohypoparathyroidism type 1a. Int J Obes. 2013;37(8):1147-53.

6. Thiele S, de Sanctis L, Werner R, Grötzinger J, Aydin C, Jüppner H, et al. Functional characterization of GNAS mutations found in patients with pseudohypoparathyroidism type Ic defines a new subgroup of pseudohypoparathyroidism affecting selectively Gsa-receptor interaction. Hum Mutat. 2011;32(6):653-60.

7. Weinhaeusel A, Thiele S, Hofner M, Hiort O, Noehammer C. PCR-based analysis of differentially methylated regions of GNAS enables convenient diagnostic testing of pseudohypoparathyroidism type Ib. Clin Chem. 2008; 54(9):1537-45.

8. Elli FM, de Sanctis L, Ceoloni B, Barbieri AM, Bordogna P, Beck-Peccoz P, et al. Pseudohypoparathyroidism type la and pseudopseudohypoparathyroidism: the growing spectrum of GNAS inactivating mutations. Hum Mutat. 2013;34(3):411-6.

9. Mann JB, Alterman S, Hills AG. Albright's hereditary osteodystrophy comprising pseudohypoparathyroidism and pseudopseudohypoparathyroidism. With a report of two cases representing the complete syndrome occurring in successive generations. Ann Intern Med. 1962;56(2):315-42.

10. Bastepe M. The GNAS locus and pseudohypoparathyroidism. Adv Exp Med Biol. 2008;626:27-40.

11. Kelsey G. Imprinting on chromosome 20: tissue-specific imprinting and imprinting mutations in the GNAS locus. Am J Med Genet C Semin Med Genet. 2010;154C(3):377-86.

12. Bastepe M, Fröhlich LF, Linglart A, Abu-Zahra HS, Tojo K, Ward LM, et al. Deletion of the NESP55 differentially methylated region causes loss of maternal GNAS imprints and pseudohypoparathyroidism type Ib. Nat Genet. 2005;37(1):25-7.

13. Chillambhi S, Turan S, Hwang DY, Chen HC, Juppner H, Bastepe M. Deletion of the noncoding GNAS antisense transcript causes pseudohypoparathyroidism type Ib and biparental defects of GNAS methylation in cis. J Clin Endocrinol Metab. 2010;95(8):3993-4002.

14. Dixit A, Chandler KE, Lever M, Poole RL, Bullman H, Mughal MZ, et al. Pseudohypoparathyroidism type $1 \mathrm{~b}$ due to paternal uniparental disomy of chromosome 20q. J Clin Endocrinol Metab. 2013;98(1):E103-8.

15. Bastepe $\mathbf{M}$, Lane $\mathbf{A H}$, Jüppner $\mathrm{H}$. Paternal uniparental isodisomy of chromosome 20q - and the resulting changes in GNAS1 methylation - as a plausible cause of pseudohypoparathyroidism. Am J Hum Genet. 2001;68(5):1283-9.

16. Mantovani G, de Sanctis L, Barbieri AM, Elli FM, Bollati V, Vaira V, et al. Pseudohypoparathyroidism and GNAS epigenetic defects: clinical evaluation of albright hereditary osteodystrophy and molecular analysis in 40 patients. J Clin Endocrinol Metab. 2010;95(2):651-8.

17. Pérez de Nanclares G, Fernandez-Rebollo E, Santin I, Garcia-Cuartero B, Gaztambide S, Menéndez E, et al. Epigenetic defects of GNAS in patients with pseudohypoparathyroidism and mild features of Albright's hereditary osteodystrophy. J Clin Endocrinol Metab. 2007;92(6):2370-3.

18. Mariot V, Maupetit-Méhouas S, Sinding C, Kottler ML, Linglart A. A maternal epimutation of GNAS leads to Albright osteodystrophy and parathyroid hormone resistance. J Clin Endocrinol Metab. 2008;93(3):661-5.

19. Juppner H. Genetic and epigenetic defects at the GNAS locus cause different forms of pseudohypoparathyroidism. Ann Endocrinol. 2015;76(2):92-7.

20. Mantovani G, Elli FM. Pseudohypoparathyroidism type lb in 2015. Ann Endocrinol. 2015;76(2):101-4

21. Lin MH, Numbenjapon N, Germain-Lee EL, Pitukcheewanont P. Progressive osseous heteroplasia, as an isolated entity or overlapping with Albright hereditary osteodystrophy. J Pediatr Endocrinol Metab. 2015;28(7-8):911-8. doi:10.1515/jpem-2014-0435.

22. Mantovani G. Clinical review: pseudohypoparathyroidism: diagnosis and treatment. J Clin Endocrinol Metab. 2011;96(10):3020-30.

23. Cacciari E, Milani S, Balsamo A, Spada E, Bona G, Cavallo L, et al. Italian cross-sectional growth charts for height, weight and BMI (2 to $20 \mathrm{yr}$ ). J Endocrinol Invest. 2006;29(7):581-93. 
24. Elli MF, de Sanctis L, Peverelli E, Bordogna P, Pivetta B, Miolo G, et al. Autosomal dominanat Pseudohypoparathyroidism Type lb: a novel deletion ablating STX16 causes loss of impriting at the A/B DMR. J Clin Endocrinol Metab. 2014:99:E724-8.

25. Gelfand IM, Eugster EA, DiMeglio LA. Presentation and clinical progression of pseudohypoparathyroidism with multi-hormone resistance and Albright hereditary osteodystrophy: a case series. J Pediatr. 2006;149(6):877-80.

26. Fernández-Rebollo E, Lecumberri B, Gaztambide S, Martinez-Indart L, Perez de Nanclares G, Castaño L, et al. Endocrine profile and phenotype(epi)genotype correlation in Spanish patients with pseudohypoparathyroidism. J Clin Endocrinol Metab. 2013;98(5):E996-1006.

27. Zazo C, Thiele S, Martín C, Fernandez-Rebollo E, Martinez-Indart L, Werner R, et al. Gsa activity is reduced in erythrocyte membranes of patients with psedohypoparathyroidism due to epigenetic alterations at the GNAS locus. J Bone Miner Res. 2011;26(8):1864-70.

28. Long DN, Levine MA, Germain-Lee EL. Bone mineral density in pseudohypoparathyroidism type 1a. J Clin Endocrinol Metab. 2010;95(9):4465-75.

29. Mantovani G, Bondioni S, Linglart A, Maghnie M, Cisternino M, Corbetta S, et al. Genetic analysis and evaluation of resistance to thyrotropin and growth hormone-releasing hormone in pseudohypoparathyroidism type lb. J Clin Endocrinol Metab. 2007;92(9):3738-42.

30. Liu J, Erlichman B, Weinstein LS. The stimulatory G protein alpha-subunit Gs alpha is imprinted in human thyroid glands: implications for thyroid function in pseudohypoparathyroidism types 1A and 1B. J Clin Endocrinol Metab. 2003;88(9):4336-41.

31. Moses AM, Weinstock RS, Levine MA, Breslau NA. Evidence for normal antidiuretic responses to endogenous and exogenous arginine vasopressin in patients with guanine nucleotide-binding stimulatory protein-deficient pseudohypoparathyroidism. J Clin Endocrinol Metab. 1986;62(1):221-4.

32. Tsai KS, Chang CC, Wu DJ, Huang TS, Tsai IH, Chen FW. Deficient erythrocyte membrane Gs alpha activity and resistance to trophic hormones of multiple endocrine organs in two cases of pseudohypoparathyroidism. Taiwan Yi Xue Hui Za Zh. 1989;88(5):450-5.

33. de Sanctis L, Bellone J, Salerno M, Faleschini E, Caruso-Nicoletti M, Cicchetti $M$, et al. GH secretion in a cohort of children with pseudohypoparathyroidism type la. J Endocrinol Invest. 2007;30(2):97-103.

34. Mantovani G, Maghnie M, Weber G, De Menis E, Brunelli V, Cappa M, et al. Growth hormone-releasing hormone resistance in pseudohypoparathyroidism type la: new evidence for imprinting of the Gsa gene. J Clin Endocrinol Metab. 2003;88(9):4070-4.

35. Mantovani G, Ferrante E, Giavoli C, Linglart A, Cappa M, Cisternino M, et al. Recombinant human $\mathrm{GH}$ replacement therapy in children with pseudohypoparathyroidism type la: first study on the effect on growth. J Clin Endocrinol Metab. 2010;95(11):5011-7.

36. Wang L, Shoemaker AH. Eating behaviors in obese children with pseudohypoparathyroidism type 1a: a cross-sectional study. J Pediatr Endocrinol. 2014;1:21.

37. Klaiman C, Quintin EM, Jo B, Lightbody AA, Hazlett HC, Piven J, et al. Longitudinal profiles of adaptive behavior in fragile $X$ syndrome. Pediatrics. 2014;134(2):315-24.

38. Dykens EM, Hodapp RM, Walsh K, Nash LJ. Adaptive and maladaptive behavior in Prader-Willi syndrome. Am Acad Child Adolesc Psychiatry. 1992;31(6):1131-6.

39. de Sanctis L, Vai S, Andreo MR, Romagnolo D, Silvestro L, de Sanctis C. Brachydactyly in 14 genetically characterized pseudohypoparathyroidism type la patients. J Clin Endocrinol Metab. 2004;89(4):1650-5.

\section{Submit your next manuscript to BioMed Central and we will help you at every step:}

- We accept pre-submission inquiries

- Our selector tool helps you to find the most relevant journal

- We provide round the clock customer support

- Convenient online submission

- Thorough peer review

- Inclusion in PubMed and all major indexing services

- Maximum visibility for your research

Submit your manuscript at www.biomedcentral.com/submit
Biomed Central 